\title{
Origin of Severe Acute Respiratory Syndrome Coronavirus 2 (SARS-CoV-2) and COVID-19
}

\author{
Roger W. Byard ${ }^{1} \cdot$ John Hunsaker ${ }^{2} \cdot$ Michael Tsokos $^{3}$
}

Accepted: 29 September 2020 / Published online: 26 October 2020

(c) Springer Science+Business Media, LLC, part of Springer Nature 2020

A recent paper published in Forensic Science Medicine and Pathology by Santurro et al. provided useful details of postmortem investigations and sampling in cases of suspected or probable COVID-19 [1]. A follow up Letter to the Editor from Zhan et al. has stated that these authors were "unscientific and irresponsible to claim that COVID-19 originated in China". They also state that the origin of the new coronavirus may not be in Wuhan China [2].

It should be clearly stated that Santurro et al. did not mention Wuhan, China, in their Technical Report and, in fact, asserted only that a cluster of cases of pneumonia due to SARS-CoV-2 originated in China. The latter fact seems reasonably non-controversial. Given that there was actually no statement that "COVID-19 originated in China" it is difficult to see that the Santurro paper needs correction. A decision was made by the Senior Editors of FSMP to publish this correspondence to enable the original authors to demonstrate that they were in no way "unscientific and irresponsible" and also to demonstrate how incorrect reading of papers may lead to imprecise and unfortunate conclusions.

\section{References}

1. Santurro A, Scopetti M, D'Errico S, Fineschi V. A technical report from the Italian SARS-Co V-2 outbreak. Postmortem sampling and autopsy investigation in cases of suspected or probable COVID-19. Forensic Sci Med Pathol. 2020;16:471-6.

2. Zhan M-J, Huang Y, Deng Z-H. Regarding "A technical report from the Italian SARS-Co V-2 outbreak. Postmortem sampling and autopsy investigation in cases of suspected or probable COVID-19.” Forensic Sci Med Pathol. https://doi.org/10.1007/ s12024-020-00322-4

Publisher's note Springer Nature remains neutral with regard to jurisdictional claims in published maps and institutional affiliations.
Roger W. Byard

roger.byard@sa.gov.au

1 Adelaide Medical School, Level 2, Room N237, Helen Mayo

North, The University of Adelaide, Frome Road, Adelaide,

South Australia 5005, Australia

2 University of Kentucky, Frankfort, KY, USA

3 Charité University, Berlin, Germany 